\title{
Multifaceted study on a cytochalasin scaffold: lessons on reactivity, multidentate catalysis and anticancer properties
}

\author{
Mehdi Zaghouani, ${ }^{[a]}$ Oscar Gayraud, ${ }^{[b]}$ Vincent Jactel, ${ }^{[b]}$ Sébastien Prévost, ${ }^{[a, b]}$ Ambre Dezaire, ${ }^{[a, c]}$ \\ Michèle Sabbah, ${ }^{\left[{ }^{[c]}\right.}$ Alexandre Escargueil, ${ }^{[c]}$ Thanh-Lan Lai, ${ }^{[d]}$ Christophe Le Clainche, ${ }^{[d]}$ Nathalie \\ Rocques, ${ }^{[\mathrm{e}]}$ Stéphane Romero, ${ }^{[\mathrm{e}]}$ Alexis Gautreau, ${ }^{[\mathrm{e}]}$ Florent Blanchard, ${ }^{[\mathrm{f}]}$ Gilles Frison, ${ }^{[\mathrm{g}]}$ and Bastien \\ Nay*[a,b]
}

\begin{abstract}
We report an intramolecular Diels-Alder reaction efficiently accelerated by Schreiner's thiourea, to build a functionalized cytochalasin scaffold (periconiasin series) amenable to biological purpose. DFT calculation highlighted a unique multidentate cooperative hydrogen bonding in this catalysis. The deprotection endgame afforded a collection of diverse structures and showed the peculiar reactivity of the Diels-Alder cycloadducts upon functionalization. Biological studies revealed strong cytotoxicity of a few compounds on breast cancer cell lines, while preserving actin polymerization.
\end{abstract}

\section{Introduction}

Cytochalasin natural products have provided some of the most useful chemical tools for cellular biology. ${ }^{1}$ Cytochalasins $B$, and mostly cytochalasin D (1, Figure 1), are indeed powerful actin polymerization inhibitors, targeting the barbed ends of actin filaments. ${ }^{2}$ Other interesting biological properties were reported, like the inhibition of glucose transporters, ${ }^{3}$ while related compounds proved to be cytotoxic like periconiasins, ${ }^{4}$ which make this family of natural products relevant to anticancer research. However, only little biology-oriented synthetic achievements have been described on cytochalasins, ${ }^{5-7}$ probably due to the reputedly high toxicity of cytochalasins $B$ and $D$. Periconiasins A-C (2-4) were recently isolated from a Periconia plant-associated fungus (Figure 1). ${ }^{4}$ Their originality not only relied on their remarkable cytotoxicity on human colorectal

[a] Dr. M. Zaghouani, Dr. S. Prévost, Dr. A. Dezaire, Dr. B. Nay Muséum National d'Histoire Naturelle, Unité Molécules de Communication et Adaptation des Micro-organismes, CNRS, 57 rue Cuvier, 75005 Paris (France)

[b] O. Gayraud, V. Jactel, Dr. S. Prévost, Dr. B. Nay Laboratoire de Synthèse Organique, CNRS, Ecole Polytechnique, 91128 Palaiseau (France)

E-mail: bastien.nay@polytechnique.edu

[c] Dr. A. Dezaire, Dr. A. Escargueil, Dr. M. Sabbah Sorbonne Université, INSERM, Laboratoire de Biologie du Cancer et Thérapeutique, Centre de Recherche Saint-Antoine, 75012 Paris, (France)

[d] Dr. T.-L. Lai, Dr. C. Le Clainche

Institute for Integrative Biology of the Cell (I2BC), CEA, CNRS, Université Paris-Sud, Université Paris-Saclay, 91198 Gif-sur-Yvette cedex (France)

[e] N. Rocques, Dr. S. Romero, Dr. A. Gautreau

Laboratoire de Biochimie, CNRS, Ecole Polytechnique, Université Paris-Saclay, 91128 Palaiseau (France)

[f] Dr. F. Blanchard

Institut de Chimie des Substances Naturelles, CNRS, 1 Avenue de la Terrasse, 91198 Gif-sur-Yvette Cedex (France)

[g] Dr. Gilles Frison

Laboratoire de Chimie Moléculaire, CNRS, Ecole polytechnique, Université Paris-Saclay, 91128 Palaiseau, France

Supporting information for this article is given via a link at the end of the document. adenocarcinoma cell lines (HCT-8) at sub-micromolar concentrations - making them potential anticancer leads- but also on their peculiar structure showing for the first time a smaller nine-membered cycle, instead of the usual macrocyclic ring. ${ }^{8}$
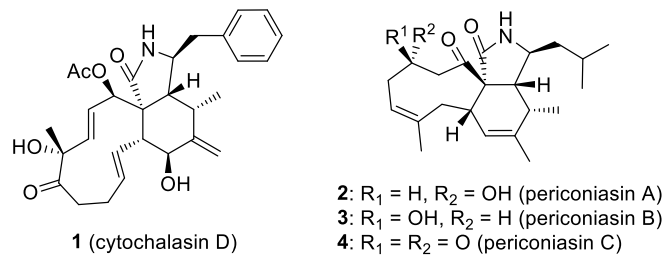

4: $R_{1}=R_{2}=O$ (periconiasin $C$ )

Figure 1. Structures of cytochalasin D (1) and periconiasins A-C (2-4) as inspiring scaffolds for biological studies.

Owing to their biological properties and simpler functionalization pattern than usually found in cytochalasins (see Figure 1), periconiasins may thus be interesting medicinal synthetic targets for anticancer purposes. The synthetic challenge of the natural products has recently been addressed by Liu and Tang who reported the first total syntheses of 2-4 and related compounds using biomimetic transformations. ${ }^{9}$ They employed an intramolecular Diels-Alder (IMDA) reaction to get the isoindolone core. Interestingly, an IMDA reaction resulting in a cyclononanecyclohexene $(9 / 6)$ bicyclic system had only been once previously described by Houk, in $1986,{ }^{10}$ which directly finds echoes with the synthesis of periconiasins. However, this IMDA transformation stands as a difficult and low yielding one.

Herein, we describe a biology-oriented synthetic work involving a thiourea accelerated IMDA reaction of triene 5 (Scheme 1) into tricyclic cycloadduct $\mathbf{6}$, before transformation of this product into periconiasin-inspired scaffolds. DFT calculations were performed to understand the origin of the thiourea effect on the cycloaddition rate, strongly supporting a multidentate interaction involving cooperative hydrogen bonding with the substrate. In addition, this study provides rich lessons on the reactivity of cycloadducts like 6 which furnished a wealth of structural diversity. Biological investigations led to the identification of two cytotoxic compounds (20 and 21), demonstrating the high biological potential of a small chemical library centered on a biologically relevant scaffold.

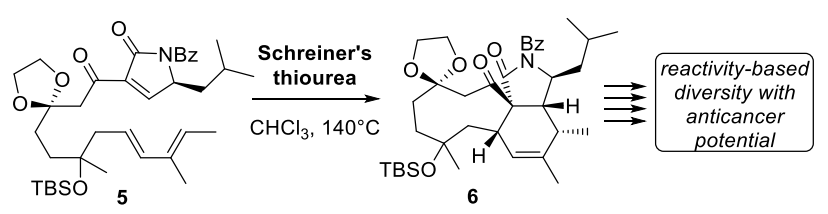

Scheme 1. A thiourea-accelerated IMDA reaction toward key cytochalasin 6 . 


\section{Results and Discussion}

The synthesis of $\mathbf{5}$ started with the protection of ethyl 3-oxo-6heptenoate $(7)^{11}$ as a 1,3-dioxolane, which was followed by the Wacker-Tsuji oxidation of the terminal olefin in presence of catalytic amounts of $\mathrm{PdCl}_{2}$ and $\mathrm{CuCl}_{2}$ in wet DMF, providing ketone 8 in $84 \%$ overall yield (Scheme 2). Interestingly, the association of microwave heating $\left(110^{\circ} \mathrm{C}, 20 \mathrm{~min}\right)$ and $p$ benzoquinone $(p-\mathrm{BQ})$ as the oxidant ${ }^{12}$ gave better and reproducible results compared to conventional heating, avoiding the formation of palladium black. Then, Barbier-type allylation of ketone 8 in the presence of $\mathrm{CoCl}_{2}$, zinc and trifluoroacetic acid (TFA) furnished tertiary alcohol $9,{ }^{13}$ which was submitted to highyielding cross-metathesis with commercial vinylboronic acid pinacol ester, in presence of Grubbs second generation catalyst. ${ }^{14}$ Microwave activation allowed decreasing catalyst loading from 10 to $1.2 \mathrm{~mol} \%$, compared to thermal heating, furnishing the olefin with perfect $E$ selectivity. The pinacol boronate product was then engaged in a boron-iodine exchange, to install $E$-iodoalkene $10(E / Z$ ratio $=4: 1)$, through a sequence of boronate hydrolysis and halogenation in the presence of $\mathrm{I}_{2} \cdot{ }^{15} \mathrm{After}$ extensive optimization of the reaction conditions, ${ }^{16}$ the SuzukiMiyaura reaction of $\mathbf{1 0}$ with freshly prepared boronic acid $\mathbf{1 1} 1^{17}$ was successfully performed in the presence of $\mathrm{PdCl}_{2}(\mathrm{dppf}) \cdot \mathrm{CH}_{2} \mathrm{Cl}_{2}$, followed by TBS-protection of the tertiary alcohol, giving 12 in $68 \%$ yield over two steps. Finally, ester saponification and carboxyl activation as an imidazole amide, ${ }^{18}$ achieved the preparation of intermediate 13, prior to dienophile installation.

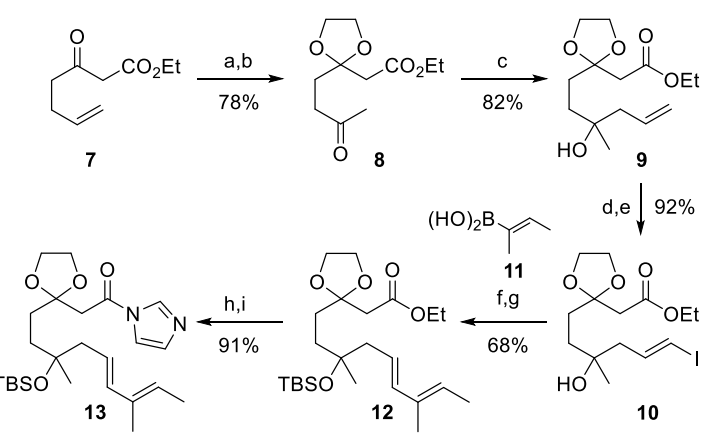

Scheme 2. Synthesis of the dienyl compound (13). Conditions: a) $\left(\mathrm{HOCH}_{2}\right)_{2}$, ( \pm )-CSA, $\mathrm{CH}(\mathrm{OEt})_{3}, \mathrm{DCM}, 20^{\circ} \mathrm{C}(93 \%) ;$ b) $\mathrm{PdCl}_{2}$ (10 mol\%), $\mathrm{CuCl}_{2} \cdot 2 \mathrm{H}_{2} \mathrm{O}(20$ $\left.\mathrm{mol} \%), p-\mathrm{BQ}, \mathrm{DMF} / \mathrm{H}_{2} \mathrm{O}(5: 1), \mathrm{MW}\left(110^{\circ} \mathrm{C}, 20 \mathrm{~min}\right)(84 \%) ; \mathrm{c}\right)$ allyl acetate, $\mathrm{CoCl}_{2}$ $\mathrm{Zn}, \mathrm{TFA}, \mathrm{CH}_{3} \mathrm{CN}, 20^{\circ} \mathrm{C}(82 \%)$; d) vinylboronic acid pinacol ester, Grubbs $2^{\text {nd }}$ generation catalyst $(1.2 \mathrm{~mol} \%), \mathrm{DCM}, \mathrm{MW}\left(120^{\circ} \mathrm{C}, 20 \mathrm{~min}\right)$ (quant.); e) (1) $\mathrm{Cs}_{2} \mathrm{CO}_{3}, \mathrm{THF} / \mathrm{H}_{2} \mathrm{O}, 20^{\circ} \mathrm{C}$; (2) $\mathrm{I}_{2}$, THF (92\% over two steps, $\left.\left.E / Z=4: 1\right) ; \mathrm{f}\right) \mathbf{1 1}$, $\mathrm{PdCl}_{2}$ (dppf) $\left.\cdot \mathrm{CH}_{2} \mathrm{Cl}_{2}(5 \mathrm{~mol} \%), \mathrm{KOH}, \mathrm{THF} / \mathrm{H}_{2} \mathrm{O}, 20^{\circ} \mathrm{C}(78 \%, E / Z=4: 1) ; \mathrm{g}\right)$ TBSOTf, 2,3,5-collidine, THF, $0^{\circ} \mathrm{C}(88 \%)$; h) $\mathrm{NaOH}, \mathrm{EtOH}, 20^{\circ} \mathrm{C}$ (quant.); i) $\mathrm{CDI}$, $\mathrm{Et}_{3} \mathrm{~N}, \mathrm{DCM}, 20^{\circ} \mathrm{C}(91 \%)$.

The reaction of 13 with the lithium salt of pyrrolidinone 14 at $78^{\circ} \mathrm{C}^{19}$ gave compound 15 in $65 \%$ yield as a mixture of stereoisomers (Scheme 3 ). After selenation of the resulting $\beta$ ketoamide, in agreement with previous reports on cytochalasin synthesis, ${ }^{20}$ dienophile $\mathbf{5}$ was released upon selenide oxidation
$\left(\mathrm{H}_{2} \mathrm{O}_{2}, \quad m\right.$-CPBA in chloroform), as a mixture of two diastereoisomers. This IMDA substrate proved to be unstable upon concentration but could be stored at low temperature as a diluted chloroform solution.

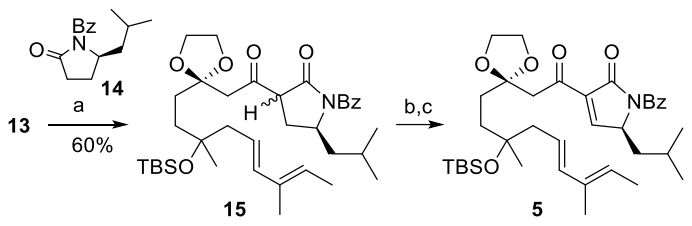

Scheme 3. Synthesis of the IMDA substrate 5. Conditions: a) 14, LiHMDS, THF $-78^{\circ} \mathrm{C}$, then 13 (65\%); b) LiHMDS then PhSeBr, THF, $-78^{\circ} \mathrm{C}(91 \%)$; c) (1) $\mathrm{H}_{2} \mathrm{O}_{2}$, $m$-CPBA, $\mathrm{CHCl}_{3},-50^{\circ} \mathrm{C} \rightarrow 0^{\circ} \mathrm{C}$; (2) sat. aq. $\mathrm{Na}_{2} \mathrm{~S}_{2} \mathrm{O}_{3}(100 \%$ conv., based on NMR, 5 was kept diluted in chloroform).

The IMDA reaction of $\mathbf{5}$ was readily undertaken after the oxidation step. An extensive array of conditions including the use of Lewis acids and organocatalysts was tested as the reaction proved to be long and difficult. Under thermal conditions at $140^{\circ} \mathrm{C}$ (sealed tubes), four days were needed to convert 5 into a separable mixture of two endo diastereoisomers, depending on the configuration at position 6 (Scheme 4), providing compounds 16 and 17 (11\% and $15 \%$ yields, respectively, over two steps from 15). The structure of $\mathbf{1 6}$ was confirmed by $X$-ray crystallography (see also the following discussion on stereochemistry). ${ }^{21}$

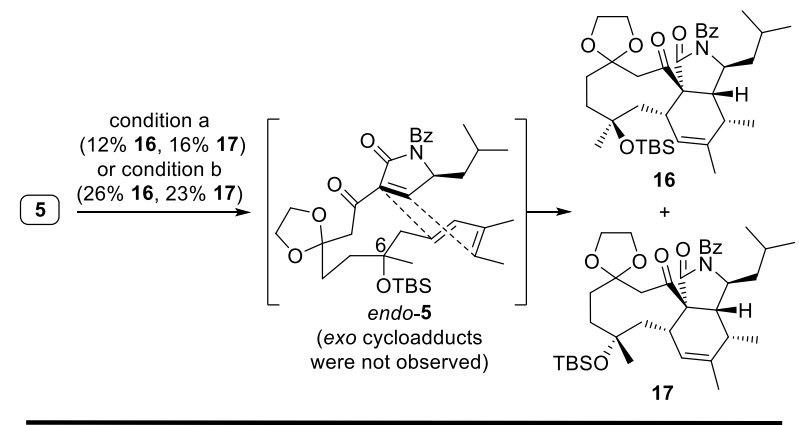

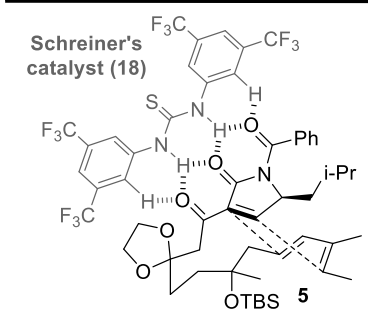

Proposed interaction of catalyst 18 with substrate $\mathbf{5}$ (see also Figure 2)

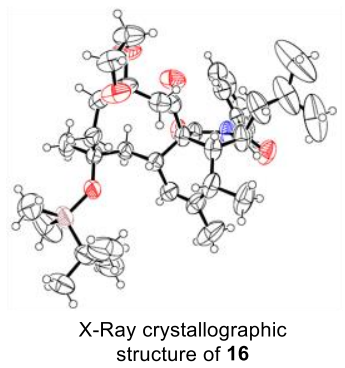

structure of 16
Scheme 4. IMDA cycloaddition step toward the periconiasin carboheterocyclic core. Conditions: a) $140^{\circ} \mathrm{C}, \mathrm{CHCl}_{3}, 4$ days; b) $18(10 \mathrm{~mol} \%), 140{ }^{\circ} \mathrm{C}, \mathrm{CHCl}_{3}, 1$ day. Yields are calculated on two steps from lactam 15. Bottom figures: Proposed binding of Schreiner's catalyst 18 to 5 (left) and X-ray crystallographic structure of 16 (right: ellipsoids are drawn at the $50 \%$ probability level and $\mathrm{H}$ atoms are shown as spheres of arbitrary radius). 


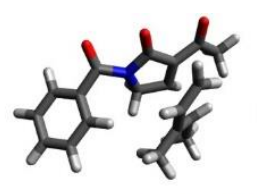

TS1 (non catalyzed)
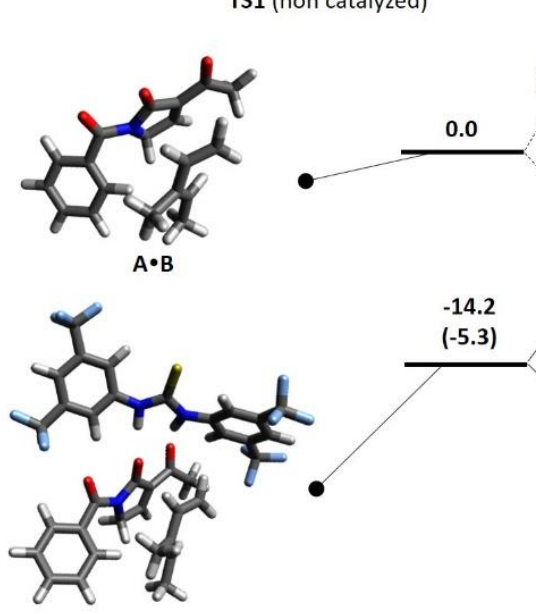

$A \cdot B \cdot 18$

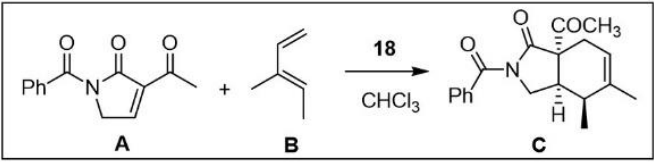

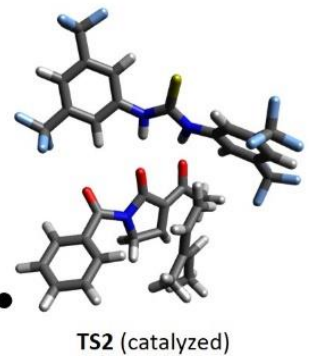

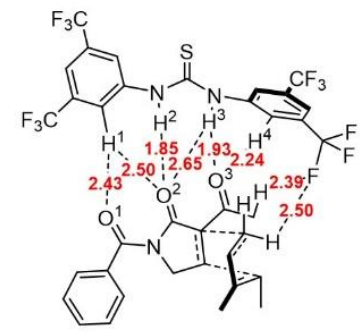

TS2 (catalyzed)
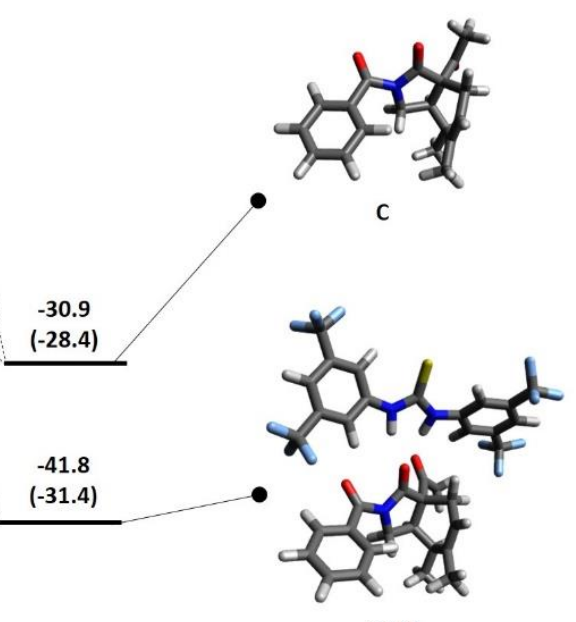

$c \cdot 18$

Figure 2. Energy profile of the Diels-Alder reaction model between dienophile $\mathbf{A}$ and diene $\mathbf{B}$ with and without thiourea $\mathbf{1 8}$. It shows the multidentate interaction and cooperative hydrogen bondings between $\mathbf{1 8}$ and $\mathbf{A}$ within transition state TS2. Hydrogen bond lengths $(\AA)$ are indicated in red numbers. The enthalpies (Gibbs free energies in parentheses) relative to the starting materials are given in $\mathrm{kcal} \cdot \mathrm{mol}^{-1}$.

The use of Brønsted or Lewis acids was attempted to accelerate the reaction, including catalytic amounts of $\mathrm{TFA}, \mathrm{Et}_{2} \mathrm{AICl}$, $\mathrm{MgBr}_{2} \cdot \mathrm{OEt}_{2}, \mathrm{ZnCl}_{2}, \mathrm{Cu}(\mathrm{OTf})_{2}, \mathrm{AgSbF}_{6}, \mathrm{Yb}(\mathrm{OTf})_{3}, \mathrm{LiClO}_{4}, \mathrm{LiBF}_{4}$, or $\mathrm{CeCl}_{3}$, yet without success, leading to degradation or no reaction in chloroform. Thiourea organocatalysts were also explored, reasoning that their multidentate character would perfectly match our 1,3,5-tricarbonylated substrate. Although dimethylthiourea and diphenylthiourea failed to improve the Diels-Alder reaction, a catalytic amount of Schreiner's thiourea $18(10 \mathrm{~mol} \%)^{22}$ allowed increasing yields to $26 \%$ and $23 \%$, respectively, and dramatically shortened reaction times to 24 hours instead of 4 days. The multidentate mode of this substrate-catalyst interaction (Scheme 4, bottom), increasing catalysis efficiency and involving cooperative hydrogen bonding, may be responsible for this remarkable effect, as evidenced by DFT modelisation (see below) Although significantly increased, the IMDA yield remained moderate and could not be improved, probably due to the high reactivity of the dienophile, leading to substrate degradation. It is worth noting that the first IMDA reaction leading to a fused $9 / 6$ bicyclic system reported by Houk and co-workers in 1986, ${ }^{10}$ performed at $155^{\circ} \mathrm{C}$ for $96 \mathrm{hrs}$ in the absence of catalyst, provided low yields and stereoselectivity (14-19\% for a cis/trans ratio of 46:54). It was improved by $\mathrm{Me}_{2} \mathrm{AlCl}$ catalysis at room temperature with a yield of $23-37 \%$ and a cis/trans ratio of $90: 10$. During the first total synthesis of periconiasins A-E, Liu, Tang and co-workers obtained the endo and exo cycloadducts in $38 \%$ and $12 \%$ maximum yields, respectively, still showing the difficulty of this reaction. In contrast, we only observed the endo-isomers 16 and 17 , in $49 \%$ global yields.
Calculation (see the SI for details) revealed close interaction of the catalyst with a model substrate, stabilizing the starting material by $14.2 \mathrm{kcal} \cdot \mathrm{mol}^{-1}$. The stabilization of the transition state is larger, which reduces the barrier of the Diels-Alder reaction by $4.9 \mathrm{kcal} \cdot \mathrm{mol}^{-1}$, and could explain the acceleration of the reaction (Figure 2). This is explained by a substantial lowering of the $\pi^{*} c c$ orbital of the polarized dienophile, by $0.91 \mathrm{eV}$, calculated in the presence of the catalyst. On the structural point of view, the thiourea adopted a twisted conformation when bound to the substrate, with the hydrogen bond network $\mathrm{H}^{2} \cdots \mathrm{O}^{2} \cdots \mathrm{H}^{3} \cdots \mathrm{O}^{3}$. Distances (1.8-2.2 $\AA$ ) were typical of those involving thioureas and carbonyl compounds ${ }^{23}$ and are the shortest for for TS2, compared to A.B.18 and C.18 (see Figure S1), in accordance with the observed effectiveness of the thiourea catalyst. The aromatic $\mathrm{H}^{1}$ was also observed in short distances (ca. $2.5 \AA$ ) with benzoyl and lactam carbonyls $\left(\mathrm{O}^{1}\right.$ and $\left.\mathrm{O}^{2}\right)$, signing secondary hydrophobic interactions. On this model, the $\mathrm{CF}_{3}$ groups also seem to have privileged interactions with the substrates, especially with the diene and the acetyl residue of the dienophile. Although this model is much simpler than our Diels-Alder substrate $\mathbf{5}$, the $\mathrm{CF}_{3}$ groups may also play an important role in substrate-catalyst interaction to stabilize the transition state. Such multidentate binding of thioureas had previously been demonstrated by Schreiner and Wittkopp on dicarbonylated $\mathrm{N}$-acyloxazolidinones, using a combination of IR, NMR and calculation experiments, ${ }^{24 a}$ and was used in intermolecular Diels-Alder reactions by the same authors. $^{24 b}$ Our cytochalasin precursor, with three $1,3,5$ successive carbonyl groups, shows larger binding energy with the 
catalyst and thus offers extended insights on this kind of cooperative multidentate catalysis.

Unexpectedly, X-ray crystallographic analyses of cycloadduct 16 (Scheme 4 and supporting information) showed this compound had crystallized as an equimolar mixture of two enantiomers, ${ }^{21}$ casting doubt on the stereochemical outcome of the reaction. An explanation of this surprising result came from the analysis of ${ }^{1} \mathrm{H}$ and ${ }^{13} \mathrm{C}, 1 \mathrm{D}$ and $2 \mathrm{D}$, NMR spectra of the unstable Diels-Alder substrate $\mathbf{5}$, showing the presence of a contaminant, which was partially assigned as enol isomer $\mathbf{1 9}$ (Scheme 5).

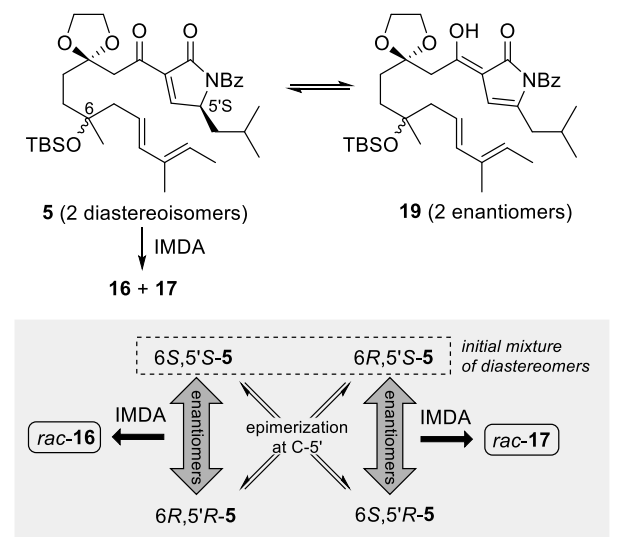

Scheme 5. Mechanism explaining the epimerization of compound 5, involving enol 19. Grey box: stereochemical consequence of epimerization at position $5^{\prime}$ on the Diels-Alder products, leading to racemic cycloadducts $\mathbf{1 6}$ and $\mathbf{1 7}$.

This epimerization reaction, previously observed with similar unsaturated lactams ${ }^{25}$ (and occasionally put to use in successful total syntheses $\left.{ }^{26}\right)$, resulted in the loss of the chiral center originated from L-leucine, in enol 19, and explains the racemic character of cycloadducts 16 and $\mathbf{1 7}$ (Scheme 5, grey box). To check the enantiomeric ratios of cycloadducts, although we were not able to derivatize debenzoylated cycloadducts by chiral reagents, both compounds 16 and $\mathbf{1 7}$ were separately analyzed by chiral HPLC (Cosmosil chiral 3B column, Figure S3). Under both reaction conditions $a$ and $b$ (Scheme 4), the two cycloadducts were found racemic, demonstrating that although dramatically accelerating the reaction, Schreiner's catalyst 18 did not prevent this epimerization. ${ }^{27}$

The structural diversity was finally uncovered from cycloadducts 16 and 17 upon deprotection attempts, revealing the peculiar reactivity landscape of these compounds (Table 1). This preliminary work was undertaken in a total synthesis context towards periconiasin A-C when Tang and Liu first reported their achievements, ${ }^{9}$ and thus brings additional reactivity insights. Disappointingly, none of the following deprotections could be applied to the synthesis of periconiasins. Classical basic hydrolytic conditions $(\mathrm{NaOH}, \mathrm{MeOH}$; entries 1 and 2) allowed selective deprotection of the lactam ring, quantitatively yielding compounds $\mathbf{2 0}$ and 21, respectively. Under weak acidic conditions $\left(\mathrm{AcOH}, \mathrm{H}_{2} \mathrm{O}\right.$; entry 3$)$ the acetal group was removed without affecting the silyl ether and the benzoyl amide of $\mathbf{1 7}$, yielding 22 in 95\% yield. The lactam group was also selectively deprotected in the presence of KF by heating in methanol (entry 4) or TBAF in THF at room temperature (entry 5), giving 21 in moderate to good yields. Increasing the temperature of the last condition to $75^{\circ} \mathrm{C}$ (entry 6) led to the concomitant cleavage of the silyl ether and resulted in bridged acetal 23 in $65 \%$ yield. HF.pyridine was unreactive towards 16 (entry 7). However, aqueous $\mathrm{HF}$ in acetonitrile afforded retro-Claisen cleavage products 25a from 16 (entry 8 ) or 24 and 25b from 17 (entry 9), all in excellent yields. The selectivity of this cleavage was dependent on the stereochemistry of the intermediary tertiary alcohol obtained from the silyl ether. We hypothesized that cleavage products $\mathbf{2 4}$ and $\mathbf{2 5 b}$ (or relatively $\mathbf{2 5 a}$ ) would arise from transient bridged acetals 27 and $\mathbf{2 8}$, formed after the double deprotection of the remote tertiary alcohol and the ketone in $\mathbf{1 7}$ (Scheme 6). The two bridged acetals may be prompt to retroClaisen $\mathrm{C}-\mathrm{C}$ bond cleavages, either leading to $\mathbf{2 4}$ or to $\mathbf{2 5 b}$ thanks to adequate bond alignment.

Table 1. Deprotection attempts of cycloadducts 16 and 17 and products thereof.
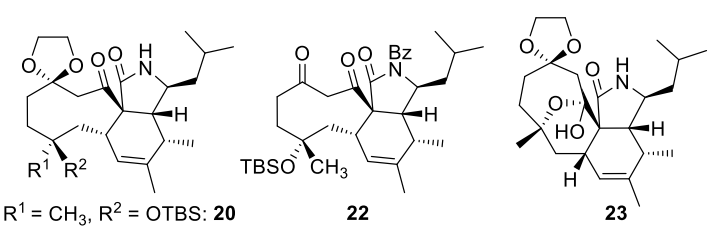

$\mathrm{R}^{1}=$ OTBS, $\mathrm{R}^{2}=\mathrm{CH}_{3}: 21$
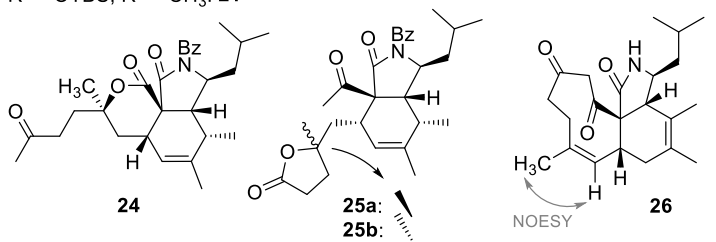

\begin{tabular}{|c|c|c|c|}
\hline Entry & $\begin{array}{l}\text { Starting } \\
\text { material }\end{array}$ & Condition & $\begin{array}{l}\text { Product } \\
\text { (yield) }\end{array}$ \\
\hline 1 & 16 & $\mathrm{NaOH}, \mathrm{MeOH}, 0{ }^{\circ} \mathrm{C}, 3 \mathrm{~h}$ & 20 (quant.) \\
\hline 2 & 17 & $\mathrm{NaOH}, \mathrm{MeOH}, 0{ }^{\circ} \mathrm{C}, 3 \mathrm{~h}$ & 21 (quant.) \\
\hline 3 & 17 & $\mathrm{AcOH} / \mathrm{H}_{2} \mathrm{O}(4: 1), 130^{\circ} \mathrm{C},{ }^{[a]} 10 \mathrm{~min}$ & $22(95 \%)$ \\
\hline 4 & 17 & $\mathrm{KF}, \mathrm{MeOH}, 150^{\circ} \mathrm{C}$, [a] $15 \mathrm{~min}$ & $21(50 \%)$ \\
\hline 5 & 17 & TBAF, THF, rt, $18 \mathrm{~h}$ & $21(85 \%)$ \\
\hline 6 & 17 & TBAF, THF, $75^{\circ} \mathrm{C},{ }^{[b]} 19 \mathrm{~h}$ & $23(65 \%)$ \\
\hline 7 & 16 & HF.py, pyridine, rt & no reaction \\
\hline 8 & 16 & aq. $\mathrm{HF}, \mathrm{CH}_{3} \mathrm{CN}, \mathrm{rt}, 2 \mathrm{~h}$ & 25a (quant.) \\
\hline 9 & 17 & aq. $\mathrm{HF}, \mathrm{CH}_{3} \mathrm{CN}, \mathrm{rt}, 2 \mathrm{~h}$ & $\begin{array}{l}24(46 \%) \\
25 b(44 \%)\end{array}$ \\
\hline 10 & 16 & $\begin{array}{l}\text { aq. } \mathrm{HCl}(1.5 \mathrm{~N}) \text {, acetone, } 140^{\circ} \mathrm{C} \text {, }{ }^{\text {[a] }} 15 \\
\min \end{array}$ & $26(17 \%)$ \\
\hline 11 & 17 & $\begin{array}{l}\text { aq. } \mathrm{HCl}(1.5 \mathrm{~N}) \text {, acetone, } 140^{\circ} \mathrm{C} \text {, [a] } 15 \\
\min \end{array}$ & degradation \\
\hline
\end{tabular}

[a] Microwave heating. [b] Sealed tube.

Finally, heating 16 in an aqueous hydrochloric acid-acetone solution (entry 10) led to complete deprotection and elimination of the OTBS group, affording compound 26 (bis-iso-periconiasin C) in $17 \%$ yield, while 17 led to degradation (entry 11). Compound 26 differs from periconiasin C (4) by the position of the two olefins. 
NOESY NMR experiments demonstrated the Z-geometry of the cyclononene olefin.

Overall, these reaction conditions provided a wealth of natural-product-like chemical diversity which is reminiscent of that found in natural cytochalasins. Indeed, highly functionalized cytochalasins are frequently found with additional modifications like bridged cycles across the macrocycle or opening of the macrocycle resulting in pendent side-chains on the isoindolone part. $^{1 \mathrm{~b}}$ We thus turned our attention to the biological potential of these compounds.

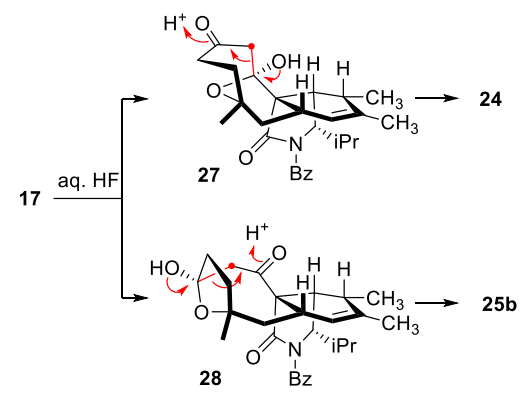

Scheme 6. Possible mechanisms explaining the retro-Claisen $\mathrm{C}-\mathrm{C}$ bond cleavage of $\mathbf{1 7}$ leading to 24 and $\mathbf{2 5 b}$.

The screening of compounds on human breast adenocarcinoma cells (MCF-7, MDA-MB-231) revealed important cytotoxicity for some of them. Compounds 20,21 and 25a were strongly cytotoxic at the concentrations $\left(\mathrm{IC}_{50}\right)$ of $0.21,1.74,2.25 \mu \mathrm{M}$ on MDA-MB231 cells, and at 1.2, 0.94 and $>2.5 \mu \mathrm{M}$ on MCF-7 cells, respectively. Videomicroscopy showed that 20 and to a lesser extent 21, both at a concentration of $5 \mu \mathrm{M}$, have significant effects on the morphology of MDA-MB-231 (Figure 3) and MCF-10A (Figure S4) cells, showing reduced motility and rounding cells which may be related to actin modifications. However, actin polymerization essays of $\mathbf{2 0 - 2 6}$ did not show any inhibiting properties of the compounds, compared to the reference compound, except an atypical decrease of the initial rate of actin polymerization in the presence of lactone $\mathbf{2 5 b}$ at micromolar concentrations. This last result clearly steers the activity of $\mathbf{2 0 , 2 1}$ and 25a towards another, yet non-elucidated, mechanism of action, and dispels an actin-based effect for these compounds.

\section{Conclusions}

The synthesis of diverse periconiasin-inspired compounds was achieved, employing an IMDA reaction efficiently accelerated by Schreiner's thiourea 18, an effect that we explained by the multidentate character of both the catalyst and the dienophile, also demonstrated by DFT calculation experiments. We hope to generalize the use of this catalyst to the synthesis of other cytochalasins currently targeted in our laboratory. In addition, although no periconiasin natural product could be reached, this work gives a straightforward access to periconiasin-like derivatives, all reminiscent of cytochalasin structural diversity. Upon biological screening, a few compounds showed important cytotoxicity on breast cancer cell lines, especially $\mathbf{2 0}$ with an $\mathrm{IC}_{50}$ of $0.21 \mu \mathrm{M}$ on MDA-MB-231 cells, opening new avenues to further biological and medicinal studies on these compounds.

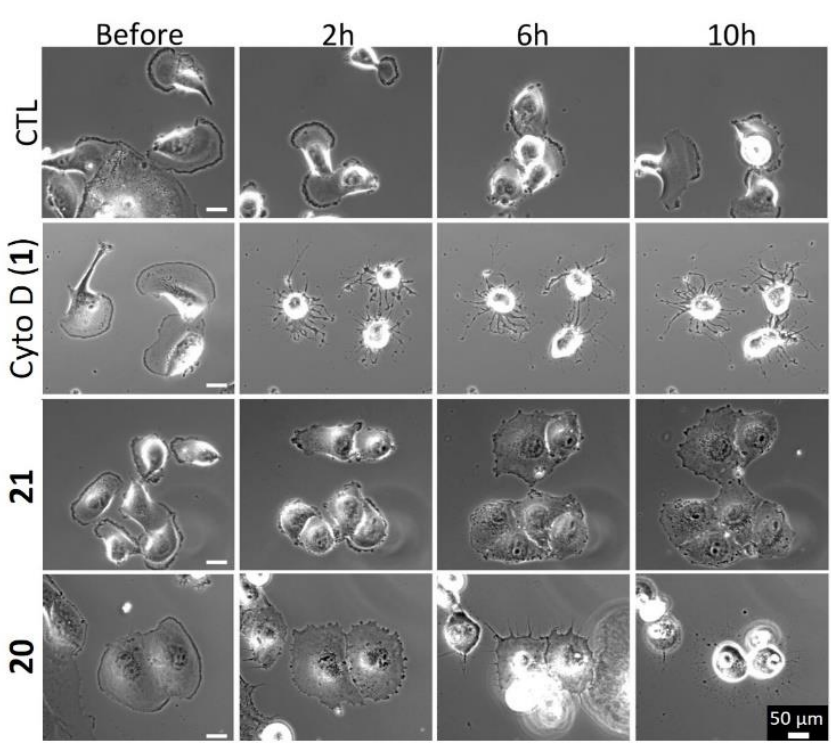

Figure 3. Effect of cytochalasin $D(\mathbf{1}$, at $2 \mu \mathrm{M})$, compounds $20(5 \mu \mathrm{M})$ and 21 (5 $\mu \mathrm{M})$ on MDA-MB-231 cells, compared to control experiment (CTL). Scale bars at $50 \mu \mathrm{m}$.

\section{Experimental Section}

Full experimental details are available in the supporting information.

\section{Acknowledgements}

The French National Research Agency (ANR) is acknowledged for funding this work and a PhD fellowship to MZ (SYNBIORG grant number ANR-12-BS07-0028-01). We thank CNRS for funding supports and ENS Lyon for a PhD grant to OG.

Keywords: Natural products • Antitumor agents • Organocatalysis $\cdot$ Medium-ring compounds $\cdot$ DFT calculations

[1] (a) M. Binder, C. Tamm, Angew. Chem. Int. Ed. 1973, 12, 370-380; (b) K. Scherlach, D. Boettger, N. Remme, C. Hertweck, Nat. Prod. Rep. 2010, 27, 869-886 (c) E. Skellam, Nat. Prod. Rep. 2017, 34, 1252-1263.

[2] J. A. Cooper, J. Cell Biol. 1987, 105, 1473-1478.

[3] A. Kapoor, J. S. Finer-Moore, B.P. Pedersen, L. Caboni, A. Waight, R. C. Hillig, P. Bringmann, I. Heisler, T. Müller, H. Siebeneicher, R.M. Stroud, Proc. Natl. Acad. Sci. USA 2016, 113, 4711-4716.

[4] D. Zhang, H. Ge, D. Xie, R. Chen, J.-h. Zou, X. Tao, J. Dai, Org. Lett. 2013, 15, 1674-1677.

[5] H. Minato, T. Katayama, M. Matsumoto, K. Katagiri, S. Matsuura, N. Sunagawa, K. Hori, S. Harada, M. Takeuchi, Chem. Pharm. Bull. 1973, 21, 2268-2277.

[6] I. Yahara, F. Harada, S. Sekita, K. Yoshihira, S. Natori, J. Cell Biol. 1982 92, 69-78.

[7] M. Sellstedt, M. Schwalfenberg, S. Ziegler, A.P. Antonchicka, H. Waldmann, Org. Biomol. Chem. 2016, 14, 50-54.

[8] Other cytochalasins have been isolated from Periconia sp.: (a) D. Zhang, X. Tao, R. Chen, J. Liu, L. Li, X. Fang, L.-Y. Yu, J. Dai, Org. Lett. 2015, 17, 4304-4307; (b) D. Zhang, X. Tao, J. Liu, R. Chen, M. Zhang, L. Li, X. Fang, L.-Y. Yu, J. Dai, Tetrahedron Lett. 2016, 57, 796-799; (c) Revision of the structure of periconiasin G: M. Zaghouani, C. Kunz, L. Guédon, F. Blanchard, B. Nay, Chem. Eur. J. 2016, 22, 15257-15260. 
[9] C. Tian, X. Lei, Y. Wang, Z. Dong, G. Liu, Y. Tang, Angew. Chem. Int Ed. 2016, 55, 6992-6996.

[10] D. A. Smith, K. Sakan, K. N. Houk, Tetrahedron Lett. 1986, 27, 48774880 .

[11] D. J. Miller, F. Yu, N. J. Young, R. K. Allemann, Org. Biomol. Chem. 2007, 5, 3287-3298

[12] W. H. Clement, C. M. Selwitz, J. Org. Chem. 1964, 29, 241-243.

[13] P. Gomes, C. Gosmini, J. Périchon, Synthesis 2003, 1909-1915.

[14] (a) H. E. Blackwell, D. J. O'Leary, A. K. Chatterjee, R. A. Washenfelder, D. A. Bussmann, R. H. Grubbs, J. Am. Chem. Soc. 2000, 122, 58-71; (b) C. Morrill, R. H. Grubbs, J. Org. Chem. 2003, 68, 6031-6034.

[15] G. Médard, Tetrahedron 2014, 70, 186-196.

[16] The direct Suzuki-Miyaura coupling of the cross-metathesis vinylboronate product with (E)-2-iodo-2-butene or its brominated equivalent provided poor yields, while protodeboronation product (back to 9) was observed in all cases.

[17] A. S. Patil, D.-L. Mo, H.-Y. Wang, D. S. Mueller, L. L. Anderson, Angew. Chem. Int. Ed. 2012, 51, 7799-7803.

[18] S. A. Harkin, R. H. Jones, D. J. Tapolczay, E. J. Thomas, J. Chem. Soc Perkin Trans. 1 1989, 489-497.

[19] M. Smrcina, P. Majer, E. Majerová, T. A. Guerassina, M. A. Eissenstat, Tetrahedron 1997, 53, 12867-12874.

[20] (a) S. M. Canham, L. E. Overman, P. S. Tanis, Tetrahedron. 2011, 67, 9837-9843; (b) E. Merifield, E. J. Thomas, J. Chem. Soc. Perkin Trans.
1 1999, 3269-3283; (c) H. Dyke, P. G. Steel, E. J. Thomas, J. Chem. Soc. Perkin Trans. 1 1989, 525-528.

[21] Crystallographic data of compound 16 are available free of charge at the Cambridge Crystallographic Data Centre under number CCDC 1479541

[22] A. Wittkopp, P. R. Schreiner, Chem. Eur. J. 2003, 9, 407-414.

[23] P. R. Schreiner, Chem. Soc. Rev. 2003, 32, 289-296.

[24] (a) P. R. Schreiner, A. Wittkopp, Org. Lett. 2002, 4, 217-220; (b) K. M. Lippert, K. Hof, D. Gerbig, D. Ley, H. Hausmann, S. Guenther, P. R. Schreiner, Eur. J. Org. Chem. 2012, 5919-5927.

[25] (a) B. B. Snider, B. J. Neubert, J. Org. Chem. 2004, 69, 8952-8955; (b) T. Kang, D. Jo, S. Han, J. Org. Chem. 2017, 82, 9335-9341.

[26] (a) N. Shionozaki, N. Iwamura, R. Tanaka, K. Makino, H. Uchiro, Chem. Asian J. 2013, 8, 1243-1252; (b) H. Uchiro, N. Shionozaki, R. Tanaka, H. Kitano, N. Iwamura, K. Makino, Tetrahedron Lett. 2013, 54, 506-511.

[27] Occasionally during this work, the IMDA reaction provided scalemic mixtures of pure compounds 16 and 17 (2:1 ratio in the best case). These observations should carefully be taken into consideration when synthesizing cytochalasins through the sequence of selenide oxidation and IMDA reaction. Any cycloadduct should be systematically analyzed to check any loss of stereoisomeric ratio. 
Graphical Abstract:

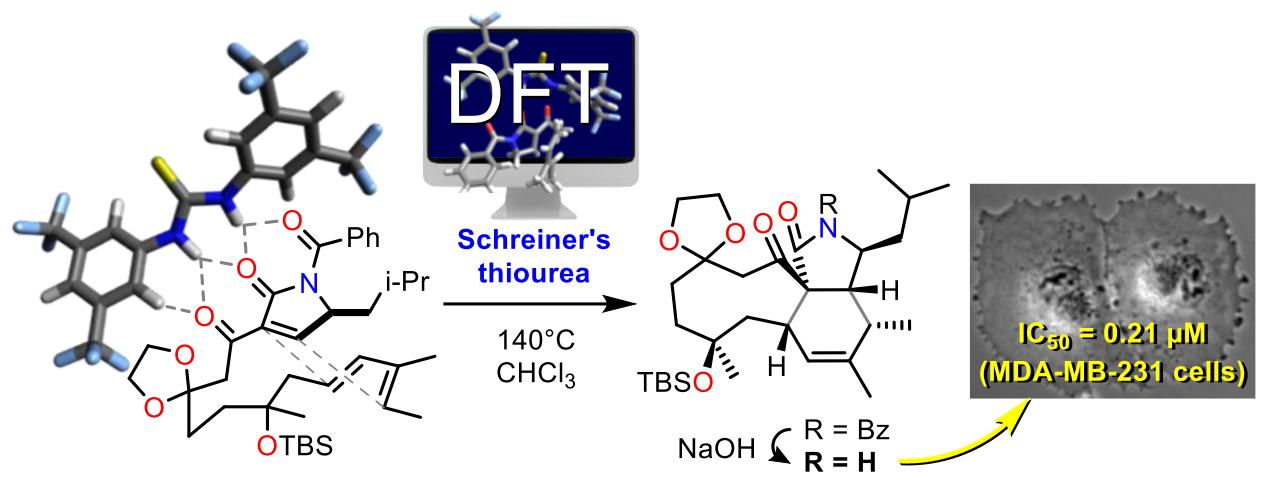

